MIDPI

MOL2NET, International Conference Series on Multidisciplinary Sciences

sciforum,

\title{
Optimization of abiotic conditions for the increased production of exopolysaccharides of bacterial species of the Rhizobium genus isolated from soil contaminated with hydrocarbons
}

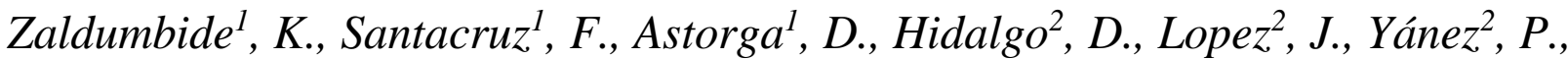 \\ Urvina ${ }^{2}$, J. y Luna ${ }^{1}, V$.
}

${ }^{a}$ Pontificia Universidad Católica del Ecuador, Faculty of Exact and Natural Sciences, Quito, Ecuador

${ }^{\mathrm{b}}$ PETROAMAZONAS EP, Environmental Technology Research Center, Joya de los Sachas, Ecuador

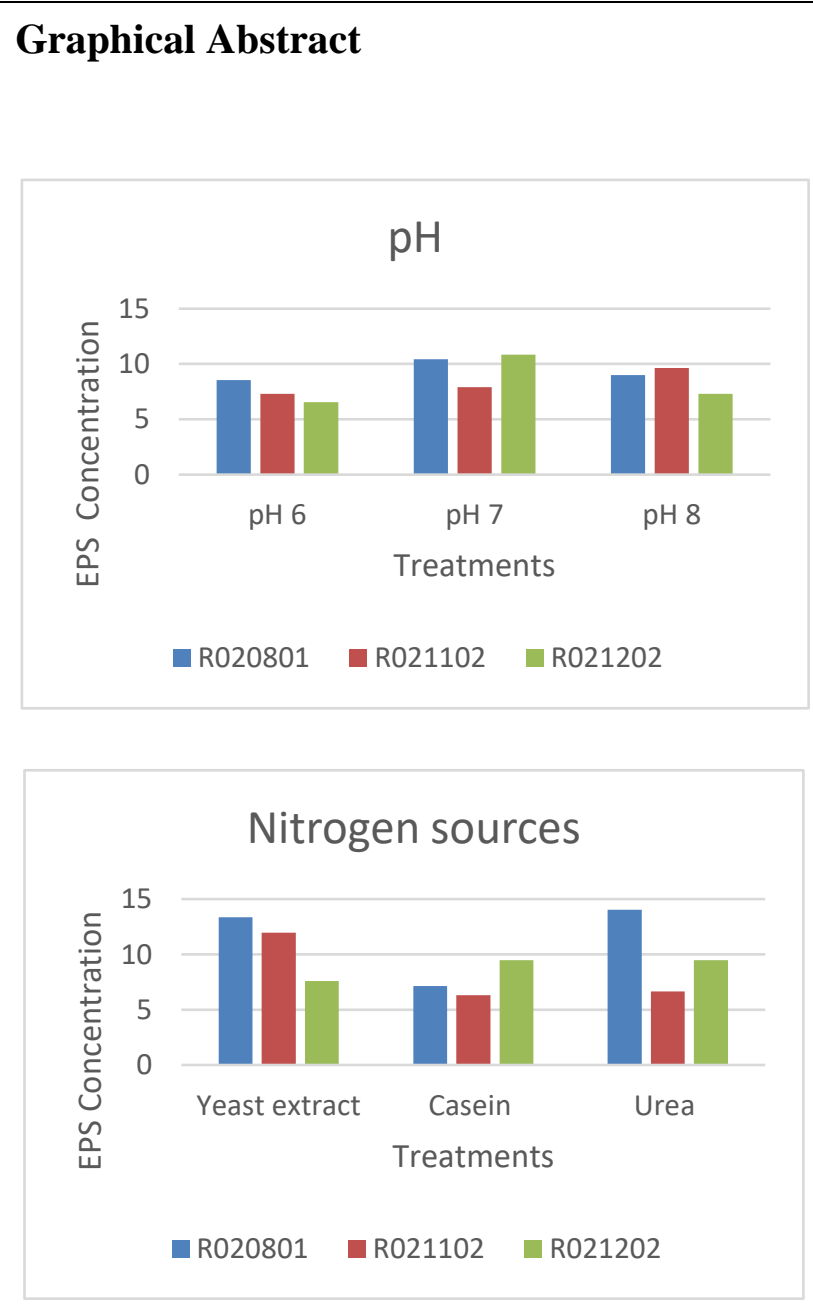

Abstract.

One of the most worrying environmental problems of the Ecuadorian Amazon is the oil spills, product of the oil exploitation [1]. To counteract the damage caused by this activity, PETROAMAZONAS-EP, through its "Live Amazon" Project (PAV), has dedicated itself to the bioremediation of soils contaminated by hydrocarbons [2]. The clay texture of the Amazonian soil is one of the factors that hinders bioremediation activities, due to its tendency to compaction and plasticization, high water retention capacity, poor aeration and low permeability [3,4,5]. All these characteristics together hinder the development of both microorganisms and plants [6]. In this context, the use of Rhizobium, a Gram-negative bacterium of free and native life of a contaminated soil, producing metabolites with a history of soil aggregation improvement such as exopolysaccharides (EPS) was proposed. This will allow the improvement of bioremediation processes, through changes in the soil structure that promote hydrocarbon degradation activity, which would result in cost reduction and saving of material and human resources in the process.

To carry out this investigation, simple random sampling was carried out in different Liability Management Centers operated by the PAV. The samples collected corresponded to plant roots with typical characteristics of nodular legumes. From the nodules, a macerate was obtained and a Gram stain was performed to corroborate the presence of Gram negative bacilli. Subsequently, these were seeded in 


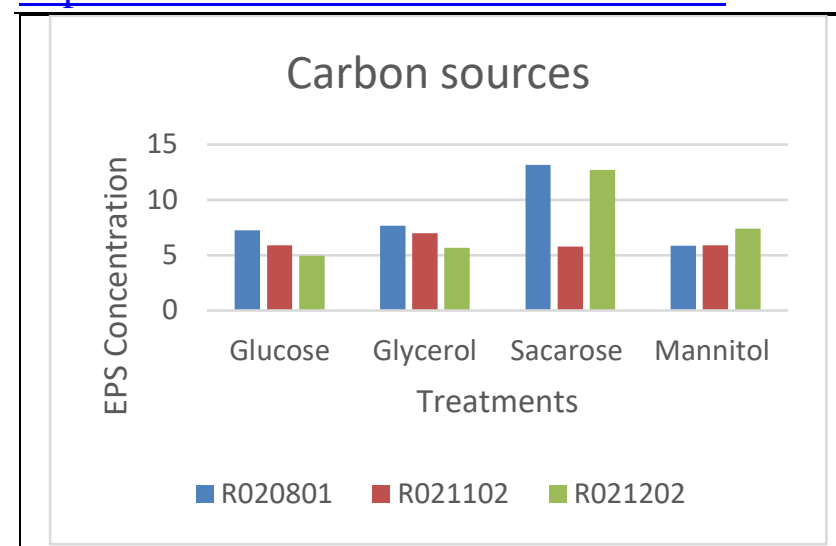

yeast-mannitol extract agar (YEMA) and the colonies that presented the common macroscopic characteristics of Rhizobium in the culture medium were selected for purification and again subjected to Gram staining to confirm the presence of gram negative bacilli.

A total of eleven isolates suspected of belonging to the Rhizobium genus were obtained. The isolates were characterized by phenotypic and biochemical tests. Phenotypic characterization was performed by describing the colonial morphology in specific media such as YEMA with Congo Red and Agar Yeast Extract- Mannitol with Bromothymol Blue. The biochemical characterization was done through catalase tests, citrate utilization, cetolactase enzyme production and antibiotic sensitivity [7]. Molecular characterization is about to be performed, using the $16 \mathrm{~S}$ rRNA analysis. The isolates obtained were subjected to a quantitative test of EPS production. The assays were performed in triplicate, for which a bacterial suspension was seeded at a concentration of $0.5 \mathrm{McFarland}$ of each strain in $10 \mathrm{~mL}$ of broth yeastmannitol extract (YEMB). EPS extraction was performed with $96 \%$ cold ethanol and centrifugation at $10,000 \mathrm{rpm}$. The quantification of EPS was carried out using the modified phenol-sulfuric acid methodology, using a glucose calibration curve as a standard. The test highlighted strains R020801, R021102 and R021202 as the higher producers of the substance of interest within the group, producing the following concentrations of EPS: $13.05 \mathrm{ug} / \mathrm{mL} ; 13.94 \mathrm{ug} / \mathrm{mL}$; and $20.77 \mathrm{ug} / \mathrm{mL}$, respectively. These isolates were used to test EPS production conditions through the modification of nutritional and physical factors in the culture medium, such as: carbon sources (mannitol as control, glucose, sucrose and glycerol); nitrogen sources (yeast extract as control, urea and casein); and different $\mathrm{pH}(6,7$ and 8$)$. The assays were in triplicate. A bacterial suspension was inoculated at a concentration of $0.5 \mathrm{McF}$ arland of each strain in 10 $\mathrm{mL}$ of yeast-mannitol extract broth modifying the corresponding conditions. EPS were recovered and quantified.

It was observed that strain R020801 and R021202 produced more EPS at $\mathrm{pH} 7$, in the presence of sucrose and urea in the culture medium. On the other hand, strain R021102 produced a higher amount of EPS at $\mathrm{pH} \mathrm{8,} \mathrm{with} \mathrm{glycerol} \mathrm{and} \mathrm{yeast} \mathrm{extract} \mathrm{in} \mathrm{the} \mathrm{culture}$ medium. At the present time, the research focuses on evaluating the production of EPS for each strain by combining the conditions previously tested. This will 


\section{References}

[1] Becerra, S., Paichard, E., Sturma, A. and Maurice. L. (2013). Living with oil pollution in Ecuador: social perceptions of health risk and responsiveness. Leader Magazine. Vol 23 [2] PETROAMAZONAS EP. (2015). Press release: Petroamazonas EP eliminated 180 sources of pollution in 14 months. 2015. Recovered from: https://www.petroamazonas.gob.ec/?p=4387 [3] Calvache, A. (2015). Soils of Ecuador. Researchgate Recovered from: https://www.researchgate.net/publication/301701400_los_suelos_del_ecuador

[4] Campaña, S. (2016). Types of soils. Scribd. Recovered from: https://es.scribd.com/document/311163645/Tipos-de-Suelos-en-El-Ecuador

[5] FAO. (2007). Topic 3: The soil, differences according to their physical and chemical appearance. Recovered from: http://www.fao.org/docrep/009/ah645s/AH645S04.htm

[6] Rucks, L. et al. (2004). Physical Properties of the Soil. Faculty of Agronomy University of the Republic, Montevideo.

Recovered

from:

http://bibliofagro.pbworks.com/f/propiedades+fisicas+del+suelo.pdf

[7] López, J. et al. (2017). Morphological and biochemical characterization of Rhizobium strains collected in common wild and domesticated beans. Rev. Fitotec 40 (1). Recovered from: https://www.revistafitotecniamexicana.org/documentos/40-1/8a.pdf 